Rosani Aparecida Alves-Souza 1 Orlando Saliba 1

\section{A saúde bucal em pauta: análise de registros dos Conselhos Municipais de Saúde de municípios pertencentes à 17a Regional de Saúde do Estado do Paraná, Brasil}

\author{
Oral health on the public agenda: \\ an analysis of Municipal Health Council \\ records in cities from the 17th Regional Health \\ Division in the State of Paraná, Brazil
}

1 Departamento de Odontologia Infantil e Social, Faculdade de Odontologia, Universidade Estadual Paulista Júlio de Mesquita Filho. Rua José Bonifácio 1193, Araçatuba, SP 16015-050, Brasil. alves-souza@uol.com.br secrdos@foa.unesp.br

\begin{abstract}
The present study analyzes interventions pertaining to oral health recorded in the minutes of meetings held by 15 Municipal Health Councils in cities from the 17th Regional Health Division of the State of Paraná, Brazil. Document analysis was performed by identifying health themes, emphasizing categorization of issues related to interventions in oral health. The most frequently analyzed themes were records concerning the programming and organization of oral health services, followed by health budget issues. In 90 of the 591 minutes studied, 134 records pertaining to oral health interventions were identified. An analysis of the latter showed that oral health interventions involve reports of actions already implemented and lack the characteristics of proposals when analyzed from the health planning perspective. This study highlights the need for dentists to expand their representation in such forums in order to play a broader role in the planning process and support oral health as a basic citizen's right.
\end{abstract}

Key words Oral Health; Health Councils; Consumer Participation

Resumo O presente estudo teve como objetivo a análise das intervenções em saúde bucal, registradas em atas de reuniões, de 15 Conselhos Municipais de Saúde, próprios de municípios pertencentes à 17a Regional de Saúde do Estado do Paraná. A análise documental deu-se a partir da identificação das temáticas em saúde, com ênfase na categorização por assunto das intervenções em saúde bucal. Os resultados evidenciaram os registros relativos à programação e organização da prestação de serviços, seguida pelo orçamento em saúde, como sendo os mais freqüentes do conjunto de temáticas analisadas. Pôde-se identificar, em 90 atas das 591 estudadas, o total de 134 registros de intervenções em saúde bucal. Por meio da análise desses últimos, percebeu-se que as intervenções em saúde bucal eram relatos de ações já concretizadas, desprovidas de características propositivas quando analisadas sob a dimensão do planejamento em saúde. Sinaliza-se para a necessidade da categoria odontológica de adquirir um maior padrão de representatividade nesses espaços, de forma a possibilitar vínculos importantes no processo de planejamento e de fortalecimento da saúde bucal enquanto direito de cidadania.

Palavras-chave Saúde Bucal; Conselhos de Saúde; Participação Social 


\section{Introdução}

A humanidade sempre compreendeu a saúde como um estado muito próximo à questão da sobrevivência e da preservação da existência, o que vale dizer que a saúde alimenta a busca para a "manutenção do seu maior legado: a vi$d a$ " (Gentile, 2001).

Através dos tempos, as concepções inerentes à saúde sempre conservaram uma certa correspondência com os vários setores do desenvolvimento humano, numa relação direta com a evolução do conhecimento em suas diversas áreas. No momento atual, reconhece-se a existência de um diálogo globalizado em prol da tão almejada qualidade de vida, o qual pode ser sintetizado pelo acréscimo dos fundamentos de vigilância à saúde ao processo de planejamento das ações pertinentes.

Apresenta-se, assim, a evolução do saber e fazer no campo da saúde pública como agente ativo dos projetos de reformulação e das intervenções, produzidas no setor saúde brasileiro, principalmente no que tange às mudanças ocorridas a partir do processo de redemocratização do país e introduz-se, ainda, a questão da participação social no contexto de promoção, proteção e recuperação da saúde.

No foco deste universo participativo em saúde é que se encontra o propósito do presente estudo, ordenado à análise e ao conhecimento da freqüência de intervenções em saúde bucal no interior dos Conselhos Municipais de Saúde (CMS) próprios dos municípios integrantes da 17a Regional de Saúde do Estado do Paraná, no período correspondente a 1990-2000.

Sem recorrer à investigação dos processos sociais e políticos que permeiam a questão da participação social, tem como intenção adicional a promoção de um despertar para a eleição dos CMS como organizadores de interferências participativas no processo local de produção das políticas públicas de saúde.

\section{Participação em saúde: estratégia capital do processo de construção social da saúde}

Um aspecto relevante a ser considerado no processo de redemocratização, marcado por intensa organização da sociedade civil, é o de que, em sua matriz ideológica, estava embutida a própria luta pela garantia do direito à saúde, em detrimento da natureza mercantilista das concepções delineadoras das políticas públicas de saúde em vigência naquela época.
Nessa perspectiva de construção social da saúde, torna-se possível aceitar que a magnitude desse movimento contribuiu para que a saúde ganhasse notoriedade na Constituição Federal de 1988, assegurando, assim, a saúde como direito de todos e dever do Estado.

Referindo-se à contemplação legal da garantia do direito à saúde, Westphal (1992) evidencia o caráter jurídico-democrático do documento constitucional, por julgar que este expressa um alto nível de consciência sanitária.

A importância do desenvolvimento de uma estrutura social capaz de assegurar condições para a busca de melhorias no setor saúde, bem como a conquista do direito, é reconhecida por Mendes (1996:62) ao apresentar que "a saúde na Constituição é definida como resultante de políticas sociais e econômicas, como direito de cidadania e dever do Estado, como parte da seguridade social e cujas ações e serviços devem ser providos por um Sistema Único de Saúde, organizado segundo as seguintes diretrizes: descentralização, mando único em cada esfera de governo, atendimento integral e participação comunitária".

Visando à ampliação e ao reordenamento das relações entre Estado e sociedade civil, a participação da população surge prevista em Lei, a qual estabelece os Conselhos e Conferências de Saúde como canais para a efetivação da participação no âmbito do Sistema Único de Saúde (SUS), localizando-os como espaços de prática da participação no processo decisório das políticas públicas de saúde e do exercício do controle social.

Alguns estudiosos, numa atitude de incentivo à participação, orientam para que esta possa ser uma constante direcionada a: "(a) conferir visibilidade aos serviços e ações de saúde sob responsabilidade do Estado; (b) conferir acesso à legislação em vigor; (c) dar visibilidade aos canais de encaminhamento de demandas ao Estado e aos fóruns institucionalizados de defesa da cidadania e do usuário dos serviços; (d) constituir e institucionalizar canais de encaminhamento direto, pelo cidadão, de demandas ao poder público; (e) ampliar o acesso às informações e conhecimentos produzidos na sociedade e fortalecimento de seus canais de expressão" (ABRASCO, 1993:12).

Ao discorrer sobre produção social da saúde, Cortes (1998) relaciona como determinantes de maior influência no processo de participação social as transformações do arcabouço institucional ocorridas recentemente, bem como as formas de organização dos movimentos populares e sindicais da localidade em questão, o tipo de aproximação entre os profissio- 
nais de saúde e líderes comunitários e sindicais; concepções e atuações dos governantes das diversas instâncias do poder e, ainda, a própria dinâmica de funcionamento dos Conselhos. Para a autora, a ocorrência da reforma do sistema de saúde e as formas de organização dos movimentos são os fatores mais decisivos dos processos participativos.

A exemplo das mudanças ocorridas, Dal Poz \& Pinheiro (1998) compreendem o processo de municipalização como sendo um fator preponderante para o funcionamento dos CMS. Argumentam que parece haver uma maior indução a um melhor desempenho das funções nos Conselhos de municípios que se encontram em estágio mais avançado do processo de municipalização, em decorrência do maior grau de autonomia na gerência dos recursos e na condução das políticas.

Nessa mesma linha de autonomia gerencial e política, cabe citar o dinamismo dos movimentos populares e sindicais (principalmente com registros históricos de movimentos de reivindicação) e a influência de alguns programas de governo, os quais podem possibilitar a participação e o controle social sobre os bens políticos.

Entende-se, assim, que a função detentora de poder exercida pelo Conselho Municipal de Saúde será sempre facilitada na presença de um território comprometido com a ampliação dos canais de participação, em reforço ao processo de descentralização das ações de saúde. Essa noção equipara-se ao entendimento de Pinheiro (1995), quando denomina a redistribuição de poder entre as instâncias do sistema de saúde de "democratização da gestão social".

O processo de descentralização se apresenta para Hortale et al. (2000) como necessário ao contexto de busca por melhorias do acesso à participação da população no processo das políticas de saúde, à qualidade dos serviços, à sustentação, à eqüidade, ao desempenho do controle social no cotidiano do setor saúde.

Vale complementar que esta relação dialética descentralização/democratização ganha expressão político-social à medida que a sociedade participa da programação e do controle das ações.

No que diz respeito ao controle social, Santos \& Carvalho (1992) elegem-no como a expressão mais viva da participação da sociedade nas decisões tomadas pelo Estado no interesse geral. Já próximo à lógica dos Conselhos de Saúde, o controle social é qualificado por Ribeiro (1997) como importante pólo influenciador de pacto político e como a principal inovação política do SUS.
Assim, todo esse capital em saúde, conquistado pela sociedade brasileira e que vem se firmando no cenário sanitário brasileiro, entendido aqui como o processo de defesa, de colaboração ao desempenho e de fortalecimento do SUS, adquirem interpretação certa como instrumentos imprescindíveis ao setor saúde.

\section{Material e método}

População de estudo: foi composta por Conselhos de Saúde de vinte municípios integrantes da 17ạ Regional de Saúde do Estado do Paraná (17a RS/PR).

População efetivamente estudada: $15 \mathrm{mu}$ nicípios, os quais providenciaram o envio da documentação necessária à elaboração do estudo, sendo eles: Bela Vista do Paraíso, Cafeara, Cambé, Centenário do Sul, Florestópolis, Guaraci, Ibiporã, Jaguapitã, Londrina, Miraselva, Pitangueiras, Porecatu, Primeiro de Maio, Rolândia e Sertanópolis.

A estruturação do estudo se baseou na análise do registro da freqüência e categorização por assunto das intervenções em saúde bucal e no reconhecimento das temáticas abordadas durante as reuniões dos CMS, servindo-se das atas correspondentes aos períodos compreendidos desde a criação e/ou implantação destes, até o mês de outubro de 2000.

Como estratégia inicial do processo operacional, procedeu-se à apresentação da intenção e do pedido de autorização para a realização do estudo à Diretoria da 17a Regional de Saúde do Estado do Paraná. A seguir, deu-se o encaminhamento de ofícios aos secretários municipais de saúde dos municípios envolvidos, a fim de formalizar o contato e o pedido de colaboração, além de explicitar os objetivos, a metodologia e a importância do estudo.

Salienta-se que a estrutura dos instrumentos utilizados para a organização e análise dos dados primou pela garantia da preservação dos assuntos comuns a todas as reuniões, além de possibilitar a categorização das áreas temáticas em saúde, a saber: responsabilidades e administração interna do CMS; orçamento em saúde; programação e organização da prestação de serviços; vigilância em saúde; comunidade e ações intersetoriais; notícias e eventos em saúde bucal.

Faz-se necessário tecer algumas considerações a respeito da documentação utilizada. Para o levantamento dos dados, serviu-se das atas registradas como sendo as de reuniões ordinárias e extraordinárias, uma vez que estavam assim classificadas na grande maioria dos documentos analisados. 
O fato das reuniões do município de Rolândia apresentarem-se registradas como plenárias ou executivas, além de ordinárias e extraordinárias, justifica a opção pela análise das atas correspondentes às reuniões plenárias, do tipo ordinárias, uma vez que as reuniões registradas como executivas, concentravam maior número de registros relacionados a assuntos internos e de caráter administrativo do Conselho de Saúde em questão. Essa conduta teve por finalidade a manutenção do padrão de representatividade social durante o processo da análise dos documentos.

Do Município de Jaguapitã, utilizou-se a totalidade das atas, uma vez que os registros não permitiram a diferenciação entre reunião do tipo plenária e do tipo executiva, isto por não haver qualquer indicativo que facilitasse a diferenciação entre os tipos citados.

Torna-se importante registrar a identificação do período de realização das reuniões, bem como o conhecimento de interrupção ou não da seqüência de realização das mesmas.

Esteve impossibilitado o conhecimento do número preciso de intervenções em saúde bucal efetivadas por cirurgiões-dentistas (quer como conselheiros, quer como usuários), em virtude da inexistência da especificação quanto à categoria profissional do ativador na maioria dos registros.

\section{Resultados}

Como pode ser observado na Tabela 1, foi permitida a identificação de 502 reuniões ordinárias, 89 extraordinárias, perfazendo um total de 591 atas de reuniões analisadas.

Com relação à freqüência de realização de reuniões do CMS, verificaram-se vários períodos de desativação de alguns Conselhos, principalmente em fases iniciais do processo de implantação destes. Encontram-se disponíveis na Tabela 1, em conformidade com os registros correspondentes à desativação, os Municípios de Bela Vista do Paraíso (1991 e 1992), Guaraci (1996), Porecatu (1996), Primeiro de Maio (1992) e Sertanópolis (1996).

Apresentando nítido direcionamento à organização da estrutura administrativa, foram muitas as atividades de caráter burocrático evidenciadas nos registros, em especial às associadas à programação e organização da prestação de serviços, seguida pelo orçamento em saúde, como pode ser visto na Tabela 2.

Recorrendo-se à análise do número de reuniões e da freqüência de aparecimento do tema saúde bucal, pode-se perceber que este en- contrava-se representado nos registros com uma freqüência de citação em 15,22\% das reuniões (Tabela 3 ).

Um esclarecimento torna-se necessário à continuidade da apresentação dos resultados, em virtude de sua relação com o objeto de maior freqüência de aparecimento nos registros de saúde bucal analisados, ou seja, a Bebê-Clínica.

O termo Bebê-Clínica deu-se como primeira denominação ao Programa de Atenção Precoce em Saúde Bucal - Odontologia para Bebês, hoje representado e desenvolvido pelo Núcleo de Odontologia para Bebês da Universidade Estadual de Londrina, Paraná. A opção pela escolha do referido termo no presente documento, deu-se em razão da equiparação aos registros das intervenções nas atas analisadas.

Portanto, pertencente aos registros de saúde bucal dos Conselhos dos municípios de Cambé, Guaraci, Ibiporã, Pitangueiras, Primeiro de Maio, Rolândia, Sertanópolis, a Bebê-Clínica pode ser identificada numa freqüência de aparecimento na ordem de 46,66\% em relação aos outros municípios pesquisados.

As práticas educativo-preventivas em saúde bucal também constaram das intervenções registradas pelos municípios de Bela Vista do Paraíso, Cafeara, Cambé, Ibiporã, Pitangueiras, Primeiro de Maio, Londrina, Porecatu, Rolândia.

Outras questões de destaque são as que se reportam à atenção odontológica a pacientes especiais, registradas pelos municípios de Cambé, Londrina e Sertanópolis.

As atas dos municípios de Cafeara, Londrina e Sertanópolis mostraram intervenções em forma de elogios aos serviços odontológicos, os quais foram compreendidos como fatores de incentivo ao exercício profissional com excelência.

Foram revelados nos registros dos municípios de Bela Vista do Paraíso, Cambé e Ibiporã alguns questionamentos relativos à inserção de ações de saúde bucal no Programa Saúde da Família (PSF). Em virtude da importância das estratégias voltadas à reestruturação organoprogramática dos serviços de saúde, cita-se o registro associado aos consórcios intermunicipais efetivado pelo Município de Cambé.

Do município de Rolândia, tem-se registrada a divulgação de resultado de estudo epidemiológico de cárie dentária, questões relativas à fluoretação da água de abastecimento público e ao encaminhamento de pacientes ao atendimento odontológico por meio de agentes comunitários.

A importância de representantes da categoria odontológica como agentes ativadores e mediadores das discussões em saúde bucal foi enaltecida diante da constatação da ocorrência de várias intervenções em saúde bucal rea- 
Tabela 1

Distribuição dos municípios segundo o número e tipo das reuniões do Conselho de Saúde

e período de análise destas. Região de Londrina, Paraná, Brasil, 2000.

\begin{tabular}{|c|c|c|c|c|}
\hline \multirow[t]{2}{*}{ Município } & \multirow[t]{2}{*}{ Período* } & \multicolumn{2}{|c|}{ Reuniões } & \multirow[t]{2}{*}{ Total } \\
\hline & & Ordinárias & Extraordinárias & \\
\hline Bela Vista do Paraíso & 1990, 1993 a 2000 & 37 & 3 & 40 \\
\hline Cafeara & 1992 a 1999 & 29 & 5 & 34 \\
\hline Cambé & 1993 a 2000 & 34 & 7 & 41 \\
\hline Centenário do Sul & 1993 a 2000 & 22 & 1 & 23 \\
\hline Florestópolis & 1998 a 2000 & 8 & 2 & 10 \\
\hline Guaraci & 1994, 1995, 1997 a 2000 & 12 & 7 & 19 \\
\hline Ibiporã & 1998 a 2000 & 15 & 1 & 16 \\
\hline Jaguapitã & 1994 a 2000 & 80 & 18 & 98 \\
\hline Londrina & 1992 a 2000 & 83 & 13 & 96 \\
\hline Miraselva & 1993 a 2000 & 18 & 4 & 22 \\
\hline Pitangueiras & 1994 a 2000 & 39 & 3 & 42 \\
\hline Porecatu & 1993 a 1995, 1997 a 2000 & 26 & 3 & 29 \\
\hline Primeiro de Maio & 1991 a 2000 & 22 & 9 & 31 \\
\hline Rolândia & 1993 a 2000 & 52 & 7 & 59 \\
\hline Sertanópolis & 1994 a 2000 & 25 & 6 & 31 \\
\hline Total & & 502 & 89 & 591 \\
\hline
\end{tabular}

* Os anos não citados na seqüência correspondem a período de desativação do respectivo Conselho de Saúde.

Principais temáticas e número de reuniões do Conselho de Saúde em que foram abordadas, segundo o município analisado. Região de Londrina, Paraná, Brasil, 2000.

\begin{tabular}{|c|c|c|c|c|c|c|}
\hline \multirow[t]{2}{*}{ Município } & \multicolumn{6}{|c|}{ Principais temáticas } \\
\hline & $\begin{array}{l}\text { Responsabilidades } \\
\text { e administração } \\
\text { interna do CMS }\end{array}$ & $\begin{array}{l}\text { Orçamento } \\
\text { em saúde }\end{array}$ & $\begin{array}{l}\text { Programação e } \\
\text { organização da } \\
\text { prestação de serviços }\end{array}$ & $\begin{array}{l}\text { Vigilância } \\
\text { em saúde }\end{array}$ & $\begin{array}{l}\text { Comunidade e } \\
\text { ações intersetoriais }\end{array}$ & $\begin{array}{l}\text { Notícias e } \\
\text { eventos }\end{array}$ \\
\hline Bela Vista do Paraíso & 24 & 24 & 34 & 14 & 7 & - \\
\hline Cafeara & 7 & 14 & 27 & 5 & 3 & - \\
\hline Cambé & 19 & 37 & 29 & 17 & 6 & 8 \\
\hline Centenário do Sul & 8 & 16 & 16 & 3 & - & - \\
\hline Florestópolis & 2 & 3 & 8 & 1 & 3 & - \\
\hline Guaraci & 7 & 11 & 14 & 3 & 2 & - \\
\hline Ibiporã & 10 & 14 & 15 & 13 & 7 & 7 \\
\hline Jaguapitã & 45 & 41 & 54 & 43 & 11 & 35 \\
\hline Londrina & 84 & 80 & 80 & 62 & 45 & 71 \\
\hline Miraselva & 6 & 15 & 12 & 3 & 1 & - \\
\hline Pitangueiras & 12 & 23 & 34 & 12 & 3 & 2 \\
\hline Porecatu & 10 & 18 & 23 & 9 & 2 & 3 \\
\hline Primeiro de Maio & 10 & 24 & 25 & 9 & 4 & - \\
\hline Rolândia & 26 & 48 & 42 & 20 & 8 & 5 \\
\hline Sertanópolis & 9 & 22 & 23 & 7 & 5 & 5 \\
\hline Total & 279 & 390 & 436 & 221 & 107 & 136 \\
\hline
\end{tabular}


Freqüência de intervenções do tema "Saúde Bucal" nas reuniões dos Conselhos Municipais de Saúde no período analisado, segundo o município. Região de Londrina, Paraná, Brasil, 2000.

\begin{tabular}{|c|c|c|c|c|}
\hline Município & Total (n) & \multicolumn{2}{|c|}{$\begin{array}{l}\text { Reuniões no período analisado } \\
\text { Com intervenções em saúde bucal }\end{array}$} & $\begin{array}{l}\text { Número total de } \\
\text { intervenções em } \\
\text { saúde bucal }\end{array}$ \\
\hline Bela Vista do Paraíso & 40 & 7 & 17,50 & 13 \\
\hline Cafeara & 34 & 5 & 14,70 & 6 \\
\hline Cambé & 41 & 11 & 26,83 & 16 \\
\hline Centenário do Sul & 23 & 2 & 8,69 & 2 \\
\hline Florestópolis & 10 & - & - & - \\
\hline Guaraci & 19 & 3 & 15,79 & 3 \\
\hline Ibiporã & 16 & 8 & 50,00 & 14 \\
\hline Jaguapitã & 98 & 7 & 7,14 & 8 \\
\hline Londrina & 96 & 14 & 14,58 & 16 \\
\hline Miraselva & 22 & 2 & 9,09 & 2 \\
\hline Pitangueiras & 42 & 4 & 9,52 & 6 \\
\hline Porecatu & 29 & 4 & 13,79 & 6 \\
\hline Primeiro de Maio & 31 & 5 & 16,13 & 8 \\
\hline Rolândia & 59 & 10 & 16,95 & 22 \\
\hline Sertanópolis & 31 & 8 & 25,81 & 12 \\
\hline Total & 591 & 90 & 15,23 & 134 \\
\hline
\end{tabular}

lizadas por cirurgiões-dentistas, membros conselheiros dos municípios de Cambé, Londrina, Rolândia e Sertanópolis. Por outro lado, referente ao município de Bela Vista do Paraíso, várias intervenções em saúde bucal estiveram contempladas, muito embora não tenha sido registrada qualquer participação ativada por cirurgião-dentista.

Na documentação do Município de Florestópolis, correspondente a 1998 e 2000, não se detectou a ocorrência de registros em saúde bucal, condição esta representada na Tabela 3.

\section{Discussão}

Pela própria natureza institucional e democrática do CMS, é permitido ao cidadão um espaço para sua co-participação no processo de produção das políticas locais de saúde. Argumenta-se que, aliada a esta permissão constitucional pró-saúde, tem-se uma forte interdependência entre o caráter permanente das reuniões do CMS e a organização institucional vigente.

Em contrapartida, na expectativa da valorização do gerenciamento participativo em saúde, ao Conselho é cobrada a busca permanente de novas alianças, respaldada por um projeto político que privilegie a democratização da saúde. Nesse processo, reverencia-se a prática da educação como modo de formação de sujeitos sociais críticos e comprometidos com os diferentes contextos epidemiológicos e assistenciais existentes.

Firmando-se nessa premissa, acrescenta-se a consideração de Kleba (2000), a qual aceita a necessidade de preparação da comunidade para uma atuação digna em saúde, em concordância com a realidade de cada comunidade.

Essa rede de acontecimentos remete ao entendimento da democratização como integrante complexa do processo da descentralização do poder, porém com habilidades essenciais para o desenvolvimento de ações pactuadas entre os diferentes pares em busca da concretização de objetivos comuns em saúde.

Reportando-se às atividades inerentes ao planejamento em saúde, Gohn (1988) recomenda ao Conselho de Saúde uma atuação de caráter permanentemente consensual ao processo dinâmico da ciência, de forma a responder favoravelmente ao surgimento de novos conceitos e formulações.

Contrário a esta noção surge, nas atas das reuniões analisadas, o predomínio de reivindicações relacionadas à contratação de recursos humanos, à aquisição de materiais e equipamentos, à carga horária profissional, à apresentação do quadro situacional da prestação de serviços, entre outros. 
Defende-se que o registro de várias intervenções relativas ao orçamento ilustra um grande avanço na sistemática de investimentos em saúde, além de apresentar-se como aliado ao princípio ético em face do destino dos próprios recursos da área. Reforça-se que esse tipo de controle poderá ser mais bem exercido quanto maior for o nível de informação em saúde existente nos segmentos envolvidos, ou seja, quanto maior for a conscientização, maior será a participação, maior poder de organização e conseqüentemente maior será o controle.

A questão da organização abre espaço para a indicação do Conselho de Saúde do Município de Londrina como corpo de grandes articulações, justificada pela diversidade das temáticas encontradas durante a análise documental. Esse caráter enriquecido não esteve fortemente evidenciado durante o estudo das atas da grande maioria dos municípios, o que vem reforçar a persistente valorização de temas administrativos de ordem interna, além de demonstrar não haver relação direta entre a temática discutida e o número de reuniões realizadas, independentemente da categorização das mesmas. O grau de atuação e a autonomia do Conselho de Saúde do Município de Londrina simbolizam um processo histórico construído de vários movimentos reivindicatórios e de participação ativa da população em defesa de seus interesses em saúde. Contudo, constatou-se não haver interesse expresso em relação a um maior número de intervenção em saúde bucal por parte dos integrantes do Conselho de Saúde.

Analisar a saúde bucal como parte integrante da saúde do indivíduo, estando inteiramente ligada às condições para uma melhor qualidade de vida, remete à aceitação dos registros em saúde bucal como um bem inerente à concepção de saúde dos responsáveis pelas intervenções realizadas.

Isso, por entender que a saúde bucal fez-se valorizada, mesmo diante do número expressivo de necessidades em saúde existentes na população e da predominância de temas próprios do gerenciamento em saúde nas pautas das reuniões dos CMS analisados.

Todavia, pode-se apreender que os temas em saúde bucal abordados não foram capazes de gerar discussões relevantes entre os participantes, dando um caráter informativo sob a forma de relatos de ações já concretizadas, isentas de compromissos gerenciais. Essa evidência realça a necessidade da categoria odontológica em adquirir um padrão maior de representatividade nos CMS, condição esta que, acertadamente, possibilitaria a geração de um vínculo diferenciado com todas as questões de saúde.
A constatação da Bebê-Clínica como referência central em grande parte das temáticas em saúde bucal identificadas pode ser explicitada pela aceitação da sua contemporaneidade ao que se apregoa quanto à formulação das políticas públicas em saúde bucal e por contabilizar importantes conhecimentos e práticas na área da atenção precoce em saúde bucal.

A questão da aceitação da Odontologia para Bebês parece encontrar respaldo, diante do resgate histórico pelo campo dos modelos em saúde bucal existentes no País até o surgimento da prática da atenção precoce. Considera-se que esta veio preencher uma lacuna no quadro de atenção e assistência em saúde bucal dirigida à clientela de 0 a 5 anos (anteriormente, os modelos e outros tipos de cuidados existentes privilegiavam escolares e casos de urgência), com conseqüente contribuição ao sistema de informação em saúde, favorecendo o incremento de dados epidemiológicos tão necessários ao planejamento e ao reordenamento das práticas em saúde bucal direcionadas à população infantil.

Numa análise temporal, compreende-se que o processo de implementação prática da Odontologia para Bebês e sua expressão político-social vêm substanciar a condição do seu reconhecimento como direito de cidadania, concedido na ocasião da 2ạ Conferência Nacional de Saúde Bucal, no ano de 1993, em Brasília, Distrito Federal (Walter et al., 1996).

Podem-se traduzir as intervenções relacionadas à atenção odontológica a pacientes especiais como condizentes ao princípio da universalização firmado pelo SUS, em virtude da providência do acesso aos serviços odontológicos desse tipo de clientela.

Os questionamentos sobre a implementação de ações de saúde bucal no PSF merecem destaque por elevarem o propósito de discussão do processo de co-responsabilidades entre os serviços de saúde e a população, bem como para uma possível reorganização da atenção (Zanetti, 2000).

Justifica-se o destaque dado à divulgação de resultado do estudo epidemiológico de cárie dentária, por meio da citação de Pinto (2000: 139), o qual se refere ao conhecimento da situação epidemiológica da população como sendo "essencial tanto para o nível de planejamento quanto para o de execução dos serviços odontológicos, constituindo-se no caminho correto de equacionamento dos problemas de saúde \& doença de cada comunidade".

A utilização do flúor na água de abastecimento público é aqui apresentada pelo fato de ter sido interpretada como indicativo de convocação da comunidade como parceira no con- 
trole do processo de fluoretação. Nessa mesma linha de raciocínio, Narvai (1998:1), ao citar que "assegurar qualidade aos produtos diminuindo ao máximo ou, se possível, eliminando os riscos à saúde de produtores e consumidores deve ser um objetivo comum dos produtores e dos órgãos do Estado", por certo, reforça a importância de parcerias em saúde.

Ao se comentar a presença do cirurgiãodentista como ativador, pretende-se motivar sua contribuição em reuniões dos CMS e em outros espaços facilitadores do exercício de sua participação cidadã, reiterando como valiosa sua participação no processo de fortalecimento da consciência preventiva em saúde bucal.

Propõe-se que o incentivo ao controle social no "processo de produção dos serviços de saúde bucal" deva ser uma bandeira - escopo a ser viabilizado e valorizado permanentemente, nos espaços permitidos ao planejamento em saúde bucal (Zanetti, 2000). Pela qualidade de direito ofertada à saúde bucal, e assim, por ser direito, pode-se expressar o direito de se decidir em saúde bucal como sendo um direito de valor imensurável!

\section{Referências}

ABRASCO (Associação Brasileira de Pós-graduação em Saúde Coletiva), 1993. Incentivo à Participação Popular e Controle Social em Saúde. Relatório Final. Brasília: ABRASCO.

CORTES, S. M. V., 1998. Conselhos Municipais de Saúde: A possibilidade dos usuários participarem e os determinantes da participação. Ciência \& Saúde Coletiva, 3:5-17.

DAL POZ, M. R. D. \& PINHEIRO, R., 1998. A participação dos usuários nos conselhos municipais de saúde e seus determinantes. Ciência \& Saúde Coletiva, 3:28-30.

GENTILE, M., 2001. Promoção da Saúde e Município Saudável. São Paulo: Vivere.

GOHN, M. G., 1988. Participação e gestão popular da cidade. Serviço Social \& Sociedade, 26:25-47.

HORTALE, V. A.; PEDROZA, M. \& ROSA, M. L. G., 2000. Operacionalizando as categorias acesso e descentralização na análise de sistemas de saúde. Cadernos de Saúde Pública, 16:231-239.

KLEBA, M. E., 2000. A participação social na construção do Sistema Único de Saúde enquanto processo de Empowerment. In: VI Congresso Brasileiro de Saúde Coletiva, Livro de Resumos, p. 56, Salvador: ABRASCO.

MENDES, E. V., 1996. Uma Agenda para a Saúde. São Paulo: Editora Hucitec.

NARVAI, P. C., 1998. Vigilância Sanitária e Saúde Bucal. São Paulo: Faculdade de Saúde Pública, Universidade de São Paulo. (mimeo.)

\section{Conclusão}

É possível pontuar os principais achados conclusivos, a saber:

- Do conjunto de temáticas em saúde, podese apreender como incipiente o estágio de democratização de alguns Conselhos de Saúde, o que é justificado pela predominância de temas burocráticos e assuntos administrativos de ordem interna.

- As intervenções em saúde bucal registradas tenderam à caracterização de ações pré-concebidas ou até mesmo já concretizadas nas redes de prestação de serviços odontológicos envolvidas, sugerindo a isenção de registros de estratégias de planejamento em saúde bucal.

- Sinaliza-se para a necessidade de a categoria odontológica adquirir um maior padrão de representatividade nos Conselhos de Saúde, a fim de contribuir com a formação de vínculos participativos em saúde e com a democratização das informações, direcionando esforços para um sistema de saúde digno e concorde às reais necessidades de saúde da população.

PINHEIRO, R., 1995. Conselhos Municipais de Saúde: O Direito e o Avesso. Dissertação de Mestrado, Rio de Janeiro: Instituto de Medicina Social, Universidade do Estado do Rio de Janeiro.

PINTO, V. G., 2000. Saúde Bucal Coletiva. São Paulo: Editora Santos.

RIBEIRO, J. M., 1997. Conselhos de saúde, comissões intergestores e grupos de interesses no Sistema Único de Saúde (SUS). Cadernos de Saúde Pública, 13:181-192.

SANTOS, L. \& CARVALHO, G. I., 1992. Das formas de controle social sobre as ações e os serviços de saúde. Saúde em Debate, 34:60-66.

WALTER, L. R. F.; FERELLE, A. \& ISSAO, M., 1996. Odontologia para o Bebê. São Paulo: Editora Artes Médicas.

WESTPHAL, M. F., 1992. Participação Popular e Politicas Municipais de Saúde: Cotia e Vargem Grande Paulista. Tese de Livre-Docência, São Paulo: Faculdade de Saúde Pública, Universidade de São Paulo.

ZANETTI, C. H. G., 2000. Saúde Bucal no Programa de Saúde da Família (PSF): Proposição e Programação. Julho $2000<$ http://www.saudebucalcole tiva.unb.br/>.

Recebido em 6 de maio de 2002

Versão final reapresentada em 13 de março de 2003

Aprovado em 21 de maio de 2003 